\title{
Ética del reconocimiento y víctimas del terrorismo
}

\section{Ethics of Recognition and the Victims of Terrorism}

\author{
XABIER ETXEBERria \\ Universidad de Deusto
}

Resumen. En este estudio se persigue el objetivo de aplicar la categoría del reconocimiento, éticamente enfocada, a las víctimas del terrorismo, tomando como referencia precisa a las víctimas de ETA. Se estructura la exposición en cuatro partes. En la primera se analiza el mal reconocimiento del terrorista, implicado en su violencia y en la interpretación que hace de ella. En la segunda se indaga la cuestión de si en estas víctimas hay una especificidad —en especial, su posible condición vicaria- que incide en el reconocimiento que se les debe. En la tercera se aborda su lucha por el reconocimiento, tratando de destacar las variaciones que aportan respecto a las teorías del reconocimiento - sobre todo en la tensión asimetría/simetría-, enriqueciéndolas. En la última parte se busca precisar el horizonte al que se aspira con esta lucha: en su diseño más general, en torno a la dignidad e identidad, y en sus objetivos más precisos de verdad, memoria, justicia y reconciliación, con la pretensión de que todo ello se sintetice convenientemente en la tríada ser reconocido-reconocer-reconocerse.

Palabras clave: reconocimiento, víctimas del terrorismo, lucha por el reconocimiento, dignidad, identidad, justicia.
Abstract. In this study, the author seeks to apply the ethical concept of recognition to the victims of terrorism, in particular, to the victims of ETA (Spain). The argument is presented in four sections. In the first section, an analysis is offered of the bad recognition on the part of the terrorist, as is implied in the violence perpetrated and in the interpretation made of it. The second section examines the issue of whether there is a specificity to these victims - particularly, its vicarious condition - that affects the recognition that is due to them. The third section of the paper addresses the struggle for recognition sustained by these victims, highlighting important variations in relation to general theories of recognition, and discussing what these variations contribute to theory development; specially in regards to the tension between symmetry/ asymmetry. In the last section, the author attempts to clarify the end goals of this struggle, in its most broad sense regarding dignity and identity, and more concretely, in terms of objectives such as truth, memory, justice and reconciliation. The expectation is that these elements synthesize in the triad be recognized-recognize-recognize oneself.

Key words: recognition, victims of terrorism, struggle for recognition, dignity, identity, justice. 
La categoría «reconocimiento» está siendo una de las referencias clave para la ética y el pensamiento político contemporáneos, compitiendo incluso con la de «justicia» ${ }^{1}$. A su favor tiene que, tal como está siendo trabajada por sus principales cultivadores, se nos presenta con intensos arraigos en la realidad, confrontada con la experiencia de mal reconocimiento en ámbitos como los de la diversidad étnica, o nacional, o de género, o de inclinación sexual, o, también, el de opresión laboral.

En este trabajo voy a focalizarla en la realidad de las víctimas del terrorismo, que tiene algo de paradójico: la reclamación de reconocimiento que hacen es manifiesta, mientras que la reflexión que aplique la categoría a ellas es escasa. Aquí ofrezco una modesta aportación ante esta laguna. Con la hipótesis de que acercar la categoría a estas víctimas es interpelador para la categoría. Y, en especial, con la intención moral de que este ejercicio reflexivo resulte provechoso para sus reivindicaciones.

El terrorismo, con unas significaciones universales básicas si es visto desde las claves del mal moral, tiene diversas expresiones. Y, condicionada como está la categoría de reconocimiento a los contextos en los que se aplica, esas expresiones modulan en parte las implicaciones de la categoría. Digo esto para subrayar que tener como trasfondo de la reflexión unas realidades terroristas $\mathrm{u}$ otras, configura la propia reflexión. El trasfondo de mis consideraciones será el del terrorismo de ETA, por tanto, el de las víctimas de ETA. Lo asumo convencido de que nos permitirá desvelar esas pautas universales a las que acabo de referirme, así como otras más contextualizadas que también serán importantes. Pero siendo consciente de que si tuviera presente, por ejemplo, ese otro terrorismo de inspiración islamista que estamos llamando global, ciertas concreciones de lo universalizable, ciertos modos de enfocar el reconocimiento y lo que exige, se presentarían de otra forma.

Estructuraré mi exposición en cuatro partes. En la primera, abordaré lo que está en el inicio: el mal reconocimiento del terrorista implicado en la violencia que ejerce y en cómo la interpreta. En la segunda, analizaré si debe hacerse una interpretación de la condición de víctima del terrorismo, específica frente a otras víctimas, que nos oriente sobre el reconocimiento debido. En la tercera, presentaré la reacción, conformada como «lucha por el reconocimiento», de estas víctimas y de quienes se solidarizan con ellas ante el mal reconocimiento sufrido. En la cuarta, definiré el horizonte al que se aspira.

\section{El mal reconocimiento sufrido por las víctimas del terrorismo}

La aspiración a ser reconocido tiene su origen más vivo en la experiencia de mal reconocimiento. En las víctimas del terrorismo, esta adquiere la contundente forma de la violencia destructora del terrorista, que encuentra su culmen en el asesinato $^{2}$. Este punto de partida pone de manifiesto que el horizonte de reconocimiento que aquí se abre se sustenta, con la correspondiente consistencia ética, en evidentes heridas morales de mal reconocimiento, que dañan radicalmente la dignidad. Pero el terrorista no se contenta con ello. Construye una interpretación tergiversadora de su acción, que eleva a un segundo nivel su mal reconocimiento. En el caso de ETA, ha adquirido varias formas.

La más burda ha tenido que ver con el fenómeno de la reificación estudiado por Honneth. Este autor ${ }^{3}$ destaca como sugerente de él que determinadas prácticas de genocidio se explican precisamen- 
te por la socialización de disposiciones reificantes del otro, que quiebran la tendencia natural del niño, en toda cultura, a reconocer intuitivamente a los diferentes como personas. Habla también de la autorreificación, que nos hace percibir nuestro mundo interior como campo fijo de entidades estables, que él aplica al impacto de los mercados capitalistas, pero que considero que puede ser proyectada al tema que nos ocupa.

¿Cómo ha funcionado esta reificación con las víctimas del terrorismo de ETA? Aunque con pasos más lógicos que temporales, puede decirse que, primero, a través de procesos de socialización, se ha dado una autorreificación en el terrorista y su mundo, en forma de construcción de identidad vasca simple y fija y, además, gravemente oprimida. Al vaciarla de toda complejización y crítica, adquiere espontáneamente formas maniqueas, en las que lo bueno propio es opuesto a lo imaginado malo del otro, visto como enemigo ${ }^{4}$. Se abre así paso a la heterorreificación de este otro, también en modos simples y estables, a través de la cual, ignorando expresamente su condición de humano en su sentido moral (cosificación como deshumanización), pasa a ser identificado total y exclusivamente con una identidad particular que se aborrece y se ve amenazante para la identidad propia, vivenciada con proyección colectiva. Con lo que, si el otro es únicamente eso, no solo se le puede sino que se le debe extorsionar y matar, en la medida en que estratégicamente se muestre eficaz para la causa de «liberación». Fijémonos que en este proceso, dado que la violencia se percibe como legitimada, tanto por el fin (considerado un derecho) como por el medio (se instrumentaliza a quien no es visto en su desnudez de humano, por tanto, al instrumentalizable), no hay autorreconocimiento de victimario, sino de héroe ${ }^{5} ; \mathrm{y}$ tampoco heterorreconocimiento de víctima, sino de opresor directo o indirecto (o de «daño colateral» inevitable).

En la medida en que las víctimas, con encomiable actitud cívica, acompañadas de un progresivo, aunque tardío, apoyo de instituciones públicas y de un sector de la ciudadanía ${ }^{6}$, han conseguido hacer socialmente relevante su lucha por el reconocimiento, en la medida, también, en que las presiones policiales, judiciales y sociales han convencido al terrorista de que estratégicamente su lucha militar estaba perdida, el discurso precedente ha sido difícil de sostener incluso para él. Es entonces cuando, sin abandonarlo pero relegándolo a la penumbra $^{7}$, han empezado a emerger en ese mundo violento o complaciente con la violencia, mecanismos ideológicos, en general solapados, con el objetivo no ya de negar frontalmente sino de diluir la realidad de las víctimas. Describo aquí dos de ellos.

El primero es el de la teoría de los «bandos enfrentados»: como ha existido terrorismo frente a ETA, en grupos como el GAL, como ha habido abuso de la fuerza en empleados públicos en su lucha contra ETA, se saca la conclusión de que «víctimas las hay en los dos bandos». Dado que reconocer como víctimas a estas personas no violentadas por ETA, con su significación propia y su alcance justo, es un deber de justicia ${ }^{8}$, ¿dónde está el mal reconocimiento? En el hecho de que al situar a todas en el marco de una conflictividad político-identitaria que el propio victimario ha definido con su lógica y sus intereses, al resistirse este a situarlas preconflictualmente en su condición moral primaria e intangible de humanos sujetos de dignidad, las asume para restar y desresponsabilizar, no para sumar y promover responsabilidades acrecentadas, comenzando por las de él. El mal reconocimiento se da ahora no 
con la negación de la condición de víctima, sino con su instrumentalización: las víctimas pasan a ser o «de las nuestras» o «de las de ellos», pasan a ser contabilizaciones al servicio de la causa, cuando la víctima en cuanto víctima, toda víctima, en sentido posesivo no es de nadie, y en sentido de solidaridad moral es de todos, más allá de quién la haya victimado.

El segundo mecanismo de dilución de la realidad de las víctimas es el de la ampliación no discerniente del campo de estas. Se parte de que, en el significado lingüístico más amplio del término, víctima es toda persona que sufre. Es, por tanto, víctima, toda persona que ha padecido la violencia de ETA, pero también lo son, porque ciertamente sufren o han sufrido, los terroristas que murieron en enfrentamientos con las fuerzas del orden público o a consecuencia de la bomba que pretendieron colocar, los presos, sus familiares, etc. Con este acercamiento, todos son situados indistintamente en el mundo de sufrimiento que «el conflicto» ha supuesto; en todos habría que pensar, indiferenciadamente, a la hora de proponerse «superarlo». Un planteamiento como este soslaya algo que es clave para el reconocimiento de las víctimas acorde con los derechos humanos. Estos, en efecto, exigen distinguir el enfoque genérico de víctima (todo sufriente) del enfoque moral, en el que víctima es únicamente quien sufre como consecuencia de una acción u omisión injusta causada responsablemente por otro humano, que quebranta su dignidad. No hacer esta distinción es una grave forma de mal reconocimiento hacia las víctimas del terrorismo: porque con ello, en ámbitos de violencia, se diluye la distinción decisiva entre víctimas y victimarios - estos también pueden sufrir-, añadiéndose a la confusión la afrenta; porque no se reconoce a las víctimas en lo que propiamente son, víctimas en sentido moral; porque, con ello, se desactivan las medidas que este último modo de reconocimiento reclama a favor de ellas; y porque, con ello, se pretenden diluir las responsabilidades de los victimarios.

\section{Sobre la especificidad de la} condición de víctima del terrorismo

Las víctimas de cualquier violencia comparten el mal reconocimiento de su dignidad. Desde este punto de vista, la reclamación de buen reconocimiento es similar en todas ellas. Asumido esto podemos preguntarnos si, además, cada tipo de victimación tiene características específicas que inciden en la concreción del reconocimiento debido. Por lo que se refiere a las víctimas del terrorismo, se afirma esta singularidad cuando se postula para ellas su condición vicaria.

En su significado más común, «vicario» es quien ejerce funciones de otro, por delegación o por sustitución. Al aplicarlo a las víctimas del terrorismo, implica, pienso, ciertos contagios de su uso religioso, como cuando se indica, dentro del cristianismo, que la muerte en cruz de Jesucristo tiene un carácter vicario sacrificial, en la medida en que, para el creyente, en un sentido teológico que desborda el histórico-político sin negarlo, es un sacrificio por la salvación de los hombres.

Concretamente, cuando se propone que las víctimas del terrorismo de ETA tienen un carácter vicario, se tienden a hacer consideraciones que estructuro y desarrollo del siguiente modo: a) el terrorismo, por definición, al elegir a sus víctimas, no pretende la mera victimación de ellas, sino que a través de ellas busca prioritariamente impactar - expansividad del terror - al conjunto de la colectividad, lograr adhesiones de unos y miedos de otros, quebrando así las es- 
tructuras políticas democráticas; b) esto supone que en las víctimas mismas se provocan daños que son de una doble naturaleza: personales, ciertamente, afectándoles frontalmente a ellas y a sus allegados; pero también públicos, afectando a la víctima no meramente en cuanto persona sino en su condición de ciudadana, y a través de ello, al conjunto de la ciudadanía, a la sociedad en general; c) por eso, estas víctimas no son un mero conjunto de individuos violentados por un colectivo de asesinos y extorsionadores, sino que las pretensiones de los victimarios, selladas con su violencia en ellas las convierten, incluso aunque no lo quieran, en la representación privilegiada de la sociedad atacada, con lo que, también en ellas, no están en juego únicamente sus derechos individuales en cuanto víctimas, sino, además, la concreción de la vida democrática y del lugar que debe tener el uso de la fuerza en ella; d) por tanto, en cierto sentido, han sufrido por todos los ciudadanos, todo demócrata está de algún modo «sustituido» en ellas - condición vicaria-.

Esta propuesta así argumentada tiene su consistencia e incide en el reconocimiento que se debe a las víctimas del terrorismo, por ejemplo, como se señalará luego, en su plasmación en la memoria y el relato públicos. De todos modos, también pueden hacerse de ella usos inadecuados, con el correspondiente impacto negativo. Comenzando por lo más obvio, hay quienes, a partir de ella, llegan a la conclusión frívola de que «todos somos víctimas», frívola en cuanto que, una vez más, mal reconoce a las víctimas directas de la violencia, subsumiéndolas indiferenciadamente en la sociedad victimada, ignorando sus dimensiones personales intransferibles y desactivando su potencial interpelador. El buen reconocimiento, incluso dentro de este enfoque vicario, exige mantener la distinción de- cisiva entre las que propiamente son víctimas y la ciudadanía que ha sido dañada en el daño a ellas.

Por lo que se refiere a las víctimas más propias, el que, por la intencionalidad terrorista de atentar contra la sociedad, se conviertan objetivamente en símbolo efectivo de la agresión sufrida por el Estado de Derecho, no debe derivar en la asignación a ellas de responsabilidades especiales. Esto es, ante esa representatividad no buscada por ellas, las víctimas pueden tener diversas reacciones, desde sentirse abrumadas a sentirse estimuladas para su acción social; y decidir a partir de ahí, de acuerdo a sus procesos de duelo y sus discernimientos personales, sus compromisos. Lo que quiero indicar con esto es que su victimación, el reconocimiento que se les debe por ella, les da derecho a intervenir socialmente, les da autoridad moral especial cuando su intervención está en el nivel prepartidario del testigo moral, les permite plantear esa intervención no solo como lucha por su reconocimiento sino como lucha por las libertades que el terrorismo intenta atenazar, pero no les fuerza a más obligación pública que la de no responder con violencia, la de respetar en su reacción al Estado de Derecho atacado en ellas?.

Por otro lado, esta representatividad de las víctimas implicada en su condición vicaria, no sustituye a la representatividad democrática para la toma de decisiones en los diversos campos, incluidos los que tienen que ver con la administración de la justicia al victimario o las estrategias de paz. José María Ruiz Soroa hace una consideración que veo pertinente ${ }^{10}$ : las víctimas, además de la dimensión personal de su victimación, son símbolo de algo que les supera, el Estado de Derecho agredido, pero esa simbólica que les supera pertenece propiamente a este Estado. 
Esta última observación nos da pistas para abordar otra cuestión que puede encontrarse implícita en un cierto malestar de algunas víctimas de violencias no terroristas. Presienten que con enfoques como el de víctimas vicarias, se establece una jerarquía entre víctimas, estando en la cúspide de ellas las de la violencia terrorista. Pero, ¿por qué, por ejemplo, una víctima de la violencia de género debería ser considerada menos víctima que una víctima del terrorismo, cuando ha podido sufrir mucho más, también con radical injusticia? Ante esta sospecha de jerarquización en el reconocimiento, que puede ser resentida como injusticia, la reacción que se tiene a veces es la de interpretar todas las violencias en clave de terrorismo, para igualarlas, y así, hablar, siguiendo con el caso, de «terrorismo de género». Pero con ello no se hace más que generar confusión. Ante lo cual, primero, es importante hacerse cargo de que ese plus simbólico que tiene la víctima del terrorismo le desborda, no puede apropiárselo, quedando desmontada la desigualdad personal entre clases de víctimas ${ }^{11}$; en segundo lugar, que es bueno que cada colectivo de víctimas sea reconocido por el hecho compartido de la victimación, pero también por las características diferenciales de ella, no solo porque afinará lo que tiene que implicar este reconocimiento en torno a cuestiones como la justicia y la reparación, sino también porque estimulará precisas medidas político-sociales tendentes a evitar nuevas víctimas. El impulso de fondo tiene que ser el de que reconocer a una víctima de una violencia, la que sea, en cuanto víctima, incluye un dinamismo que empuja a reconocer a todas; pues de lo contrario, a la primera no se la reconocería ya en cuanto víctima sino en cuanto otra cosa. Igualmente, la expectativa de las víctimas de un determinado tipo de violencia de ser reconocidas en cuanto víctimas, queda afinada moralmente cuando en ella anida una predisposición a la solidaridad con expectativas similares de los otros tipos de víctimas.

\section{La lucha por el reconocimiento de las víctimas del terrorismo}

Confrontándose con la experiencia de mal reconocimiento, en la víctima surge la expectativa de ser reconocida, de la que hablan autores como Ricoeur o Honneth ${ }^{12}$, que emana, como señala este último, con un comentario que en la víctima del terrorismo se cumple en su radicalidad, de una experiencia de ser tratada injustamente que implica una gran conmoción, hasta el punto de impactar a la identidad personal. Con todo, la expectativa es, como tal, una actitud pasiva, aunque tenga la virtualidad activa de la interpelación. Pasa a activa cuando deriva en lucha por el reconocimiento.

3.1. Hegel, en el marco de su teoría, señala que la lucha por el reconocimiento es algo propio del estado de naturaleza, en el que los hombres se oponen como autoconciencias singulares, pero que deja de tener sentido donde surge el Estado, pues, en el ser común que crea, cada uno es reconocido por sí mismo y por los otros: la lucha ha fundado la sociedad, pero constituida esta, queda externa a ella, es disruptivo pretender que siga $^{13}$. Ahora bien, la lucha por el reconocimiento de las víctimas del terrorismo nos muestra una dinámica mucho más compleja que esta sucesión temporal en la que tanto hay de constructo. Implica un proceso en el que se presupone un reconocimiento - el mutuo reconocimiento cívico en el Estado democrático- que el terrorista quiebra con su violencia, generando una grave afrenta moral ante la que se reacciona con la lucha por recuperar ese reconocimiento 
perdido — porque no adviene automáticamente-, pero - cuestión importante- con modulaciones nuevas, pues deberá incluir de modo memorialmente efectivo ese pasado.

La complejización de la dinámica se acrecienta al hacernos cargo de que el terrorista etarra sitúa su mal reconocimiento de las víctimas en lo que considera lucha por el reconocimiento de la identidad nacional vasca. La inmoralidad de su enfoque radica en que afronta esto último, en sí algo del nivel partidario que pide «luchas» escrupulosamente democráticas, quebrantando los requerimientos del reconocimiento más primario $\mathrm{y}$ universal, el que tiene que ver con la dignidad.

La lucha por el reconocimiento, al menos en su versión fuerte, parte ineludiblemente de una asimetría. Se suele presuponer que su horizonte adecuado es el de lograr la simetría. En este sentido, el reconocimiento mutuo es considerado como una referencia clave para definir la justicia en una sociedad. Honneth lo expresa así: «Las sociedades solo representan estructuras legítimas de ordenación, en la medida en que estén en condiciones de garantizar unas relaciones fiables de reconocimiento mutuo en distintos niveles», a través de la correspondiente institucionalización de los principios del reconocimiento ${ }^{14}$. Conviene aclarar que esta mutualidad no precisa necesariamente ser simétrica para ser adecuada. Es lo que pasa en la esfera familiar. Pero en la esfera pública, la del ciudadano, el reconocimiento no solo mutuo sino simétrico parece imponerse: es el que remite a la igualdad jurídica de los individuos que disfrutan de los mismos derechos. Según este esquema, la violencia terrorista, situada en esta esfera, podría ser definida como la quiebra de este criterio, y la superación de ella como su recuperación. Es decir, el reconocimien- to simétrico y recíproco - el reconocimiento entre iguales-, sería, como tal, normativo; además, para decirlo con palabras de Taylor, la única solución satisfactoria al mal reconocimiento.

Pero cuando confrontamos el esquema con el mal reconocimiento de las víctimas del terrorismo y su lucha por el reconocimiento adecuado, constatamos que peca de simple y que, incluso, puede prestarse a derivaciones moralmente incorrectas. Para evidenciar su problematicidad comencemos recordando cómo ha sido concebido este horizonte de simetría por el entorno de ETA y con frecuencia por otros sectores sociales: el conflicto violento se superará positivamente, se dice, cuando evolucione en una paz en la que, garantizado el cese de la violencia (por ambas partes, se suele añadir, según el esquema de los bandos enfrentados), se exprese en una situación pública y social en la que «no haya ni vencedores ni vencidos». En sí, esta fórmula parecería reflejar el perfecto reconocimiento simétrico. Sin embargo, a las víctimas de ETA, y a la sociedad solidarizada con ellas, les indigna, desde ese sentido de la justicia modelado a partir de la experiencia de victimación. Porque perciben que, aquí, la reciprocidad simétrica sin más no puede ser el horizonte moral: la violencia crea una asimetría de tal naturaleza que su superación no se resuelve en una mera simetría, sino en una igualdad de la ciudadanía que contemple una decisiva «huella asimétrica», concretable, entre otros modos, como memoria de la víctima que se prolonga en el futuro. Una huella así concebida no es herida para la convivencia sino su terapia y expresión más plena.

En esta revisión de la lucha por el reconocimiento de las víctimas del terrorismo desde las categorías de asimetría y simetría, hay otra cuestión que conviene tener en cuenta. En los modelos habitua- 
les, el esquema tiende a proyectarse a los directos contendientes en ella: su aplicación a nuestro caso la remitiría a lucha entre terroristas y sus apoyos y víctimas del terrorismo, con los suyos. Pero también aquí se impone revisar el modelo. Primero, porque empuja espontáneamente al constructo de los bandos enfrentados, incorrecto para lo que aquí contemplamos, como señalé en su momento. Segundo, porque, como también se indicó, si en su sentido más preciso la violencia de los terroristas afecta a sus víctimas directas, en su sentido global afecta al conjunto de la sociedad democráticamente organizada. Tercero, porque las víctimas del terrorismo, cuando reclaman reconocimiento, lo reclaman prioritaria y decisivamente al conjunto de la sociedad, que tiene el deber de autoasignarse una deuda con ellas ${ }^{15}$.

La exigencia expresa de reconocimiento a los victimarios por parte de las víctimas de ETA está afrontando un segundo momento cuando algunos de ellos, a nivel personal, han hecho procesos de revisión crítica de su pasado violento y de reconocimiento del daño que han causado, y cuando otros, a nivel colectivo, pretenden reinsertarse estratégicamente en la esfera de la igualdad jurídica. Esta exigencia es con frecuencia indirecta: se plasma en la propuesta a las autoridades públicas de condiciones que los victimarios deberían cumplir para que se les ofrezca la oportunidad de esa reinserción. No es cuestión de entrar aquí en el análisis de ellas. Lo que conviene subrayar es que pueden ser interpretadas como un mensaje no solo a las autoridades públicas, sino también a los violentos, a los que indirectamente se les vendría a decir: nos sentiremos reconocidas en lo más básico por vosotros cuando las cumpláis.

3.2. Si ser hecha víctima, forzadamente, es una pasión que ocasiona el violento en la víctima, la lucha por el reconocimiento de esta y de quienes hacen causa común con ella es, en principio y como hemos visto, una acción. Ahora bien, adentrándonos en nuevas complejidades, hay modos de pasión, problemáticos, que pueden generarse en la propia víctima que actúa, asociados a su reivindicación de reconocimiento.

Sobre el deseo de reconocimiento como pasión, que genera efectos negativos tanto para la identidad personal como para la vida social, tiene un sugerente estudio Pulcini ${ }^{16}$, sustentado en el análisis de las propuestas de Adam Smith y Rousseau sobre este tema. Estos autores proponen que la lucha por el reconocimiento (que ellos sitúan en la búsqueda de riqueza y honores para que los demás nos admiren y estimen) es negativa cuando se asocia a formas patológicas de amor a sí mismo (miméticas, de tipo imitativo o competitivo), que solo se superan positivamente si se logra un espacio interior autónomo de la influencia del otro, ya sea en la forma de «autorreconocimiento» (Smith), ya sea en la forma de «autenticidad» (Rousseau). Interesa particularmente, creo, el análisis de Rousseau, más radicalmente crítico contra la dinámica mimética, a la que atribuye la generación de una falsa identidad, la renuncia a ser uno mismo en aras del anhelo de ser reconocido por los otros. ¿Pueden las víctimas del terrorismo caer en búsquedas patológicas de reconocimiento?

Comienzo apuntando esas situaciones extremas, especialmente las de largos y duros secuestros, en las que la presión psicofísica de terrorista carcelario es de tal naturaleza que a veces consigue ser asimilado-interiorizado por su víctima, que esta, de algún modo, se sienta reconocida por él, ocultando la durísima relación de dominación. Es lo que conocemos como el síndrome de Estocolmo. Aquí la patología no emerge de 
la víctima; es introyectada por el victimario, con gran efecto destructor, porque impacta el corazón de la identidad. A la víctima que lo sufre le toca un penoso y largo camino, precisado de firmes acompañamientos, para reconducir su lucha por el reconocimiento.

Pasando ahora a otras posibilidades de patología, ¿hay en las víctimas del terrorismo propensión a un deseo de reconocimiento patológico en cuanto mimético? Es algo que vemos con facilidad en esos colectivos que luchan por tener «los reconocimientos que tiene el otro porque los tiene el otro». Pero cuando la lucha por ser reconocido brota de una victimación lacerante no es precisamente esta dinámica la que tiende a surgir. Es cierto que puede darse el fenómeno descrito por Todorov de que, aunque nadie quiere que le hagan víctima, una vez que se acoge socialmente a las víctimas, «todos queremos haberlo sido», ser reconocidas así; pero esto no afecta precisamente a las auténticas víctimas, sino a las que teniendo cierta tangencialidad a ellas pretenden aprovechamientos espurios. Es cierto, también, que, por ejemplo, en el ámbito de las víctimas del terrorismo de ETA, las víctimas de las primeras décadas reclaman con frecuencia los beneficios que están recibiendo las de la última década; pero esto no debe ser interpretado como mímesis enajenadora sino como reivindicación de equidad, pues responde al muy superior abandono que sufrieron las primeras.

$\mathrm{Si}$, por tanto, es muy rara en las víctimas del terrorismo la dinámica mimética propiamente dicha al expresar sus expectativas de reconocimiento, ¿caben otras formas en las que aparezcan dimensiones negativas, no en el sentido moral sino en el sentido de ser perjudiciales para ellas? Ricoeur hace una consideración que nos ofrece algunas pistas. Las luchas por el reconocimiento, dice, pue- den instalarse en la «conciencia desgraciada», bajo las formas de sentimiento incurable de victimación o de una infatigable postulación de ideales inalcanzables ${ }^{17}$. A veces esto tiene que ver con los procesos de duelo. Tanto en estos como en las luchas por el reconocimiento, hay una decisiva referencia memorial. Jelin nos recuerda muy bien dónde está el punto en el que el duelo se atraviesa positivamente, precisamente en relación con la memoria: en el momento en el que en la víctima lo dominante no es ya el que «sufra» la memoria de victimación, sino el que «la trabaje», el momento en el que «a diferencia de la repetición traumática, el pasado no invade el presente, sino que lo informa» ${ }^{18}$. Entonces, esa memoria se convierte en fuerza al servicio de su autonomía, no en presión que la bloquea o deforma. La herida seguirá existiendo, pero como herida cicatriza$\mathrm{da}^{19}$. Y la víctima estará en condiciones de protagonizar una fecunda lucha por el reconocimiento.

Incluso si se realiza positivamente este proceso hay víctimas del terrorismo que, embarcadas por largo tiempo en la lucha por ser reconocidas, manifiestan su cansancio en seguir sosteniendo pública y activamente su condición de víctimas y su deseo de pasar a dar relevancia social y personal a otras dimensiones de su identidad. Con ello nos señalan algo importante. La ciudadanía, social y políticamente organizada, desde la antes citada categoría de «deuda», tiene el deber de implicarse establemente en la lucha por el reconocimiento de las víctimas. Pero estas lo que tienen, desde el punto de vista cívico, es un derecho a hacerlo, no un deber, que concretan a través de su discernimiento libre (en el que jugarán las vivencias de victimación, las convicciones, las relaciones, etc.). Tener esto presente es la mejor vía para que su implicación social se aleje de modelos 
que la «instalen» en la «conciencia desgraciada».

\section{El horizonte de la lucha por el reconocimiento de las víctimas del terrorismo}

La lucha por el reconocimiento de las víctimas del terrorismo no tiene únicamente una motivación reactiva ante la violencia sufrida. Está impulsada por el horizonte de reconocimiento al que aspira, que es el que le da orientación y sentido.

4.1. En su forma genérica, puede concebirse como aspiración a que sea reconocida la dignidad de la víctima y a que, en consecuencia, se abra para ella la vía de la justicia, pero, también, la de la vida buena en una identidad lograda. Voy a apoyarme en el debate entre Fraser y Honneth - aunque ellos ignoren la temática del terrorismo- para desarrollar esta afirmación. Creo, en efecto, que podemos obtener luces de él, sin que, para la cuestión que nos interesa, sea necesario tomar partido en él ${ }^{20}$. Más bien, lo que propongo es hacer determinadas articulaciones entre las categorías que manejan.

Honneth hace más explícita que Fraser la referencia a la dignidad. Así, señala que, hoy, «el objetivo normativo parece no ser ya la eliminación de la desigualdad, sino la prevención de la humillación o del menosprecio; las categorías centrales de esta nueva visión ya no son la distribución equitativa o la igualdad de bienes, sino la dignidad y el respeto»; panorama ante el que él opta por la tesis de que «el reconocimiento de la dignidad de personas o grupos constituye el elemento esencial de nuestro concepto de justicia» ${ }^{21}$, subsumiendo en él los conflictos de distribución. Esta tesis conecta espontáneamente con las víctimas del terrorismo, cuya reclamación básica es que se les reconozca con plenitud su condición de dignidad. Porque es esa condición la que han visto negada radicalmente, no meramente de palabra, sino con la contundencia brutal de la violencia destructora. Este acercamiento básico al horizonte del reconocimiento positivo tiene la ventaja de hacerse cargo, moralmente, de toda la carga emocional que está en juego en la experiencia de las víctimas $^{22}$.

De todos modos, esta primera afinidad de la expectativa de las víctimas con el enfoque de Honneth no deja en la irrelevancia al de Fraser. Porque, ¿cómo deberá tomar cuerpo esta reclamación genérica de respeto a la dignidad? Haciendo efectiva, con toda su radicalidad, la paridad participativa —en la que la autora sintetiza reconocimiento y distribución justa - de las víctimas en cuanto «ciudadanas víctimas». Señalé en su momento que en la victimación terrorista hay, imbricadas, una herida personal y cívica. En el terrorismo de ETA esto ha sido manifiesto, pues las elecciones de víctimas que ha hecho, motivadas por sus objetivos ${ }^{23}$, eran de dos tipos: o porque sustentaban el funcionamiento del Estado, o porque tenían opiniones y opciones políticas que contradecían los supuestos de la banda. Esto es, su victimación más «proclamada» y «autojustificada» ha estado encaminada expresamente a quebrar el derecho a la paridad en el ejercicio público de la autonomía, que certifica el disfrute de la dignidad. Lo que supone a contrario que reclamar la paridad participativa para aquellos a los que ETA se la negó es fundamental como horizonte de reconocimiento. Con todo, habría que añadir algo a esta aplicación del enfoque de Fraser. La paridad es, por definición, simétrica; pues bien, también en esta simetría habría que incluir una «huella de asimetría» encaminada a afinar la simetría: la especial re- 
levancia de la participación de la víctima para todo lo relacionado con la victimación cuando la sitúa en el nivel prepartidario de los derechos humanos.

Volviendo a la propuesta de Honneth, hay en ella algo más, que le distancia de Fraser, que pretende ser estrictamente deontológica: la referencia teleológica del primero, aunque sea en su versión tenue o formal, a la identidad y autorrealización. Honneth nos viene a decir: que el reconocimiento positivo de los otros significativos es necesario para la identidad lograda; y que esta es, a su vez, el presupuesto para la buena autorrealización, aunque quede en manos del sujeto definirla ${ }^{24}$. Lo que significa que el horizonte de este reconocimiento, no es meramente el respeto a la dignidad, sino un respeto que potencie esta identidad que capacita para la autorrealización ${ }^{25}$.

Este tema del reconocimiento ligado a las identidades no solo individuales sino colectivas - etnoculturalmente marcadas, en especial- es fuente de constantes debates. Pero aquí no nos corresponde entrar en ellos, pues considero, por lo que se verá enseguida, que no es este el campo en el que se mueve la problemática del reconocimiento de las víctimas del terrorismo. A pesar de lo cual, sí pienso que el horizonte de reconocimiento de estas está conexionado con la identidad.

Una violencia terrorista como la etarra incluye entre sus consecuencias más palmarias la convulsión de las identidades de los supervivientes, e, incluso, el intento de tergiversación de las identidades de los asesinados. No está, por eso, de sobra, señalar que lo que debe perseguir el reconocimiento es la restauración de la identidad de la víctima, para que sea identidad lograda. El reconocimiento, se suele concretar, de «los otros significativos». Para la víctima del terroris- mo estos son, por supuesto, los de sus círculos familiares, de amistad y de referencia, los más capaces de aliviar su herida psico-moral; pero también la sociedad socio-políticamente organizada, en la que puede afrontar la herida cívica. Respecto a los victimarios y su potencial reconocimiento de la víctima, que tiene que implicar asunción sincera y plenamente coherente del daño injusto causado, con dolor moral por haberlo hecho, las víctimas no los consideran espontáneamente como otros significativos en la reconstrucción de su identidad, y entre ellas hay posturas varias respecto a su apertura a pedirlo y acogerlo si viene. Este dato tendría que ser interpelador y revelador - del significado de lo que ha hecho y de lo que le toca hacer- para el terrorista que pretenda abrirse a la víctima.

La identidad pública de la víctima que el terrorista ha convulsionado es, prioritariamente, identidad cívica, a la que está subordinada cualquier referencia etnocultural que la concrete. Volviendo al caso de ETA, en la intención primaria de esta, se ha violentado a la víctima porque ha sido percibida como implicada en los pilares que sostienen la identidad política española. Pero, en realidad, la violencia se ha dirigido contra sus derechos cívicos (a la vida, a la integridad psicofísica, a la libertad de expresión y participación...), ejercidos en su caso en el marco del Estado español (y, en contadas ocasiones, francés). Esto es, lo determinante es que a la víctima se le ha dañado en su identidad cívica universal. Por eso, ella, aunque contextualizada en su particularidad como no puede ser de otro modo, es, en realidad, víctima que simboliza lo universal de los derechos humanos vulnerados. La restauración de su identidad a través del adecuado reconocimiento tiene que expresarse como restauración de esta identidad cívi- 
ca plena, desde la que, evidentemente, ejercerá sus derechos con libertad y autonomía en el ámbito de la pluralidad legítima, particularizándola en sus horizontes de autorrealización personal y cívica.

Esto último puede entenderse mejor a partir de la afirmación de Ricoeur, que también conexiona reconocimiento e identidad, de que «la que exige ser reconocida es, sin duda, nuestra identidad más auténtica, la que nos hace ser lo que somos» ${ }^{26}$. Es cierto que queremos que se nos reconozca no como mera representación de la universalidad, sino en nuestra particularidad legítima, en la identidad con la que nos autoidentificamos libre y personalizadamente. Por eso, cuando se produce la restauración cívica en la víctima, materializando el buen reconocimiento, hay que concebirla no solo como condición de posibilidad de que se concrete en la autoidentificación que decida, sino como reconocimiento anticipado de esta identidad particularizada ${ }^{27}$.

En esta conexión entre reconocimiento e identidad, Ricoeur aporta otra observación sugerente. Nos recuerda que la identidad personalizada está decisivamente asociada al poder de narrarse, es identidad narrativa, ligada a la dimensión temporal e histórica. Desde esta perspectiva, en la identidad de la víctima quedará sellada para siempre, en el relato que la define, la victimación que sufrió. La restauración, aquí, apoyada por el buen reconocimiento, se logra cuando es una síntesis entre la buena memoria de lo sucedido, que hace frente al olvido pero también a la fijación en el pasado que petrifica la identidad, y la buena promesa que sustentándose en la justicia y creatividad hacia el futuro reconstruye con novedad esa identidad (generándose así, en la víctima, una dialéctica entre idem e ipse, para decirlo con terminología del autor).
4.2. Tras esta presentación del horizonte más genérico de la lucha por el reconocimiento, paso ahora a mayores concreciones. Es ya algo consagrado que las víctimas aspiran a la verdad, la memoria y la justicia. Es una cuestión discutida si hay que aspirar a la reconciliación. Aquí me voy a limitar a apuntar cómo estas exigencias se conexionan con el reconocimiento.

Resulta manifiesto que este está decisivamente ligado a la verdad: se reconoce a las víctimas en cuanto víctimas, en su alcance y en su sentido, si se hace verdad plena sobre lo que pasó, porque es lo que las hizo víctimas. A su vez, se accede a esta verdad recorriendo sus diversas vías: a) la de las «huellas» corporales y materiales que dejó la violencia, siendo la más reveladora el cadáver de la persona asesinada; b) la del testimonio de las víctimas supervivientes y sus allegados, inevitablemente sustentado en interpretaciones, con su riqueza y sus límites, pero latiendo siempre en él la cercanía máxima con el hecho violento y lo que ha supuesto; c) la vía judicial definida por la imparcialidad en el análisis de pruebas, que dicta sentencias que certifican no solo la existencia de la víctima, sino también la del victimario y su responsabilidad; d) la del saber de la historia, en la que su lógica de explicación e interpretación tiene que ponerse al servicio de la representación honesta del pasado, que incluye conexionarlo con el bien y el mal de acuerdo a una imparcialidad que no se identifica con la neutralidad $^{28}$; e) la vía, por último, de la verdad social, la que asume el grueso de la población, modulada por los grandes agentes socializadores - la familia, la escuela, los grupos de iguales, los medios de comunicación, los partidos políticos, las organizaciones sociales - y lo que pretenden conseguir de cara al futuro cuando miran al pasado violento. 
La aproximación plena a la verdad se da cuando hay una firme imbricación entre estas diversas vías, gracias a la cual unas fecundan y purifican a las otras. También es así para el caso de las víctimas de ETA. Respecto a ellas: hay ya una significativa verdad testimonial de las víctimas, y voluntad en sectores sociales, políticos y académicos, de ir agrandándola; hay una importante verdad judicial, pero, igualmente, un espacio relevante en el que no se ha podido aportar su luz, por lo que queda como tarea pendiente a la que no se debe renunciar; respecto a la verdad histórica queda mucho por hacer, porque las historias que se han hecho hasta ahora son más «historias de ETA» que de las víctimas, habiendo aquí, por tanto, un reto importante para los historiadores ${ }^{29}$; en cuanto a la verdad social es en estos momentos, a la vez, la más frágil y amenazada por parcializaciones, tergiversaciones y olvidos, y la que las víctimas más reclaman y precisan, puesto que es esa la verdad con la que conviven, en la que más propiamente se sienten bien o mal reconocidas.

Pasemos ahora a la cuestión de la memoria. Podría decirse que supone el hacerse cargo de la verdad de forma mantenida en el tiempo, esto es: desde el presente en que se recuerda, retomando el pasado en donde sucedió lo recordado y proyectándolo al futuro que se quiere modelar; y haciendo que esa verdad siga siendo una referencia viva, intrasubjetiva e intersubjetiva, en la sucesión de generaciones. La conexión del horizonte de memoria con el reconocimiento se da de varias formas. Esa memoria: a) es la única vía para reconocer a los asesinados; b) hace que el reconocer no sea un mero acontecimiento puntual que se desvanece con su finalización: si nuestra identidad se realiza y despliega en la temporalidad, también así tiene que desplegarse el re- conocimiento que pretende remitirse a ella, en formas vivas, reconfiguradas con interpretaciones emergentes en las nuevas generaciones. Para que se trate de reconocimiento memorial pleno, la memoria en juego deberá sintetizar en su forma propia, los diversos acercamientos a la verdad que antes se mencionaron.

Una memoria así, como expresión de reconocimiento, se materializa en los procesos de socialización, en forma relevante, el que tiene lugar en la educación reglada y no reglada. Es muy importante que en ellos se avive a través de la presencia de las víctimas, incluso su presencia física, pedagógicamente enmarcada. Se materializa también, de una manera más literal, en las conmemoraciones, monumentos, homenajes. Son importantes y delicados, por lo que hay que estar atentos a no caer en abusos ${ }^{30}$.

En cuanto al referente de la justicia, está unido al horizonte de reconocimiento en la medida en que, como señalé, certifica quién es víctima, en qué modo, con qué intensidad. Pero, además, quién ha sido $s u$ victimario, asignándole la correspondiente responsabilidad y penalización. Que las víctimas se sienten reconocidas cuando se hace esta justicia y que, en cambio, se sienten abandonadas cuando hay impunidad, es manifiesto. La exigencia de justicia y no impunidad, por eso, es ineludible ${ }^{31}$. Esto no presupone que no convenga debatir en torno a los dos grandes enfoques de la justicia penal hoy existentes: el que enfatiza la dimensión retributiva - para el que es muy relevante que el castigo recibido por el victimario se aproxime lo más posible, dentro de los derechos humanos, al daño que él causó-; y el que enfatiza la dimensión restauradora, de la víctima pero también del victimario. Un modo de entender esta última, por la que personalmente considero que hay que avanzar, es distinguir en la justicia entre las medidas 
reparadoras y restauradoras directamente dirigidas a la víctima -incluyendo lo que en ello le corresponda hacer al victimario-, que se muestran irrenunciables, y la dirigida directamente al victimario - normalmente en forma de castigo carcelario - que se propone esté fuertemente orientada a su restauración y sobre la que se está dispuesto a hacer reducciones y transformaciones si el culpable cumple las condiciones éticas pertinentes.

Por último, unos apuntes relativos a la reconciliación como horizonte del reconocimiento. Está presente ya en Hegel. Sería precisamente ella la que sella un reconocimiento recíproco y simétrico superando una conflictividad definida por la asimetría violentadora. Con tal, por supuesto, de que se den ciertas condiciones que un comentarista de Hegel define así: «El reconocimiento implica que se supera la alteridad del otro, pero sin que sea identificada con el sí mismo, sin que sea reducida a alteridad propia. Exige que se vaya al otro y que se retorne del otro, pero quitando de este retorno toda traza de asimilación» ${ }^{32}$.

Muchas víctimas tienden a rechazar la reconciliación intersubjetiva, el reconciliarse con su victimario, que sugiere este enfoque. Desde el punto de vista de las emociones es muy costoso y desde el punto de vista de las convicciones se presta a objeciones múltiples, no entrando en cualquier caso dentro de lo exigible a la víctima, aunque creo que hay que apoyar a la que opte por adentrarse, con prudencia, en él. De todos modos, cabe un acercamiento social a la reconciliación, en el cual lo que se busca es la reintegración cívica del victimario, no necesariamente su reconciliación personal con la víctima, poniéndole las correspondientes condiciones, unas relativas a su asunción honesta del civismo y otras relativas a sus deberes con las víctimas que causó. Personalmente pienso que es una vía que hay que explorar, con toda la lucidez y prudencia que demanda. $\mathrm{Si}$ se es de esta opinión, será muy importante subrayar que la reconciliación de la que hablemos no tendrá que pretender ser simétrico-recíproca; una vez más, deberá estar «contagiada» de una asimetría moral - el camino que recorren víctimas y victimarios no tiene nada de «equivalente»-, que se contrapone a la asimetría inmoral de la violencia para ser su justa contrapartida ${ }^{33}$.

4.3. En el conjunto de las consideraciones precedentes se ha ido explorando la dinámica reconocer/ser reconocido. Pero tras esta apariencia diádica late una realidad triádica, en la que el tercer elemento es «reconocerse». Hay un reconocerse liberal formal del individuo separado como sujeto de dignidad y derechos. La perspectiva hegeliana se despega de este enfoque. Es consciente de que no puede concebirse al individuo más que amparado por las relaciones sociales, con lo que, en este sentido, es la intersubjetividad lo originario y no la subjetividad, es en aquella en la que se da el ser reconocido/reconocer; y, también, el reconocerse, que ya no será meramente formal.

Este tema del autorreconocerse es muy relevante para las víctimas del terrorismo. Una violencia que se define como generadora de «terror» es enormemente desestabilizadora de la psique de las personas. $\mathrm{Si}$, para colmo, como ha sucedido en el caso del terrorismo de ETA, va acompañada del desamparo social a sus víctimas, este efecto de destrucción se acreciente fuertemente. Pues bien, ante esta turbación interior de la víctima, no solo es capital que se le reconozca adecuadamente. Es también decisivo que integre en ese heterorreconocimiento su propio autorreconocerse con plena positividad, no solo moral, sino 
también cívica. El proceso de duelo en buena medida puede ser identificado como proceso de reconocimiento de sí.

¿Cómo podríamos, quienes no somos víctimas, colaborar en lo que nos corresponda en la vivencia en las víctimas de esta dinámica triádica del reconocimiento? He ido dando diversas pistas. Aquí añado un nuevo apunte: de algún modo, todo tiene que comenzar con la atención. Alloa $^{34}$ nos recuerda una distinción de Merleau-Ponty entre «atención segunda», reflexiva, voluntaria, que se remite a actualizar saberes adquiridos, y atención primaria, ajena a nuestra iniciativa y nuestro querer, en la que el objeto no puede ser anticipado, que es actualizada por el impacto de este. Él entiende que acordar reconocimiento remite a la atención segunda, pero que lo decisivo está en la atención primera. Aquí quiero fijarme en un aspecto de esta cuestión, con estos esquemáticos comentarios: el reconocimiento de las víctimas del terrorismo comenzará positivamente cuando parta de la atención dirigida a ellas; la atención más significativa es la primaria, aquella en la que somos sorprendidos por la presencia impactante de la víctima, que nos cuestiona hasta el fondo y nos llama - según lenguaje levinasiano - a la responsabilidad (reconocer como responder); ahora bien, esta atención primaria funciona cuando tenemos ciertas disposiciones que la favorecen, cuando nos situamos en una desnudez que hace posible el ser impactado, esto es, cuando hemos desmontado los prejuicios que impiden que veamos al ser humano víctima; es relevante sostener este primer momento de reconocimiento en los reconocimientos posteriores de la «segunda atención», en la que aparece el diálogo e incluso el debate. De este modo, la finura ética del reconocimiento de las víctimas, del respeto a su centralidad y a sus espacios propios de iniciativa, estará garantizada.

\section{BIBLIOGRAFÍA}

Alonso, M., Universales del odio. Creencias, emociones y violencia, Bakeaz, Bilbao, 2004.

Alloa, «Par-delà la reconnaissance. L'attention comme paradigme por une éthique asymetrique», Alter. Revue de Phénoménologie, 18 (2010), 125-141.

Arteta, A., Mal consentido. La complicidad del espectador indiferente, Alianza, Madrid, 2010.

Bilbao, G., Por una reconciliación asimétrica. De la «geometría» del terror a la de su superación, Bakeaz, Bilbao, 2008.

Bilbao, G., Jano en medio del terror. La inquietante figura del victimario-víctima, Bakeaz, Bilbao, 2009.

Casquete, J., En nombre de Euskal Herria. La religión política del nacionalismo vasco radical, Madrid, Tecnos, 2009.

Etxeberria, X., La participación social y política de las víctimas del terrorismo, Bakeaz, Bilbao, 2007.

Etxeberria, X., Dinámicas de la memoria $y$ víctimas del terrorismo, Bakeaz, Bilbao, 2007.

Etxeberria, X., Identidad como memoria narrada y víctimas del terrorismo, Bakeaz, Bilbao, 2009.

Etxeberria, X., «Historización de la memoria de las víctimas del terrorismo en el País Vasco», en Rivera, A. y Carnicero, C. (eds.), Violencia política: historia, memoria y víctimas, Maia, Madrid, 2010, 287-316.

Fraser, N. y Honneth, A., ¿Redistribución o reconocimiento?, Morata, Madrid, 2006.

Finelli, R., «Trame del riconoscimento in Hegel», Archivio di Filosofía, 2-3 (2009), 39-47.

Hegel, F. W. F., Fenomenología del Espíritu, Valencia, Pre-textos, 2009. 
Honneth, A., «Reconocimiento y obligaciones morales», Revista Internacional de Filosofía Política, 8 (1996), 5-17.

Honneth, A., «Recognition and Justice», Acta Sociológica, 47-4 (2004), 351364.

Honneth, Reconocimiento y menosprecio. Sobre la fundamentación normativa de una teoría social, Katz, Madrid, 2010.

Jaeschke, W., «Il riconoscimento come principio dell'ordinamento statale e interstatale», Archivio di filosofía, 2-3 (2009), 189-198.

Jelin, E., Los trabajos de la memoria, Siglo XXI, Buenos Aires, 2002.

Margalit, A., Ética del recuerdo, Herder, Barcelona, 2002.

Mate, M. R., «Por una justicia anamnética», Iglesia viva, 247 (2011).

Petrucciani, S., "Giustizia e riconoscimento. Paradigmi a confronto nella filosofia politica contemporanea»,
Archivio di Filosofia, n. ${ }^{\text {s }}$ 2-3 (2009), 199-207.

Pulcini, E., «Riconoscimento, autenticità, autoriconoscimento», Archivio di Filosofia, 2-3 (2009) 209-217.

Renault, E., L'experience de l'injustice. Reconnaissance etclinique del'injustice, La Découverte, París, 2004.

Ricoeur, P., La memoria, la historia, el olvido, Trotta, Madrid, 2003.

Ricoeur, P., Caminos de reconocimiento, FCE, México, 2006.

Taylor, C., «Identidad y reconocimiento», Revista internacional de filosofia política, 7 (1996), 10-19.

Taylor, C., «La política del reconocimiento», en Taylor, C., Argumentos filosóficos, Paidós, Barcelona, 1997, 293-334.

Todorov, T., Memoria del mal, tentación del bien, Península, Barcelona, 2002.

Todorov, T., Los abusos de la memoria, Paidós, Barcelona, 2008.

\section{NOTAS}

\footnotetext{
1 Véase Fraser, N. y Honneth, A., ¿Redistribución o reconocimiento?, Morata, Madrid, 2006; Honneth, A., «Recognition and Justice», Acta Sociológica, 47-4 (2004), 351-364; Petrucciani, S., «Giustizia e riconoscimento. Paradigmi a confronto nella filosofia politica contemporanea», Archivio di Filosofia, n. ${ }^{\text {os }} 2-3$ (2009), 199-207; Renault, E., L'experience de l'injustice. Reconnaissance et clinique de l'injustice, La Découverte, París, 2004.

2 Esto último plantea ya un reto relevante y en cierta medida novedoso: el buen reconocimiento, que ha tendido a proponerse para los vivos, algo que en este caso también habrá que mantener (con los sobrevivientes y los allegados), debe encontrar su referencia más firme en su remisión a personas que ya no viven. Lo que significa que su soporte básico pivotará en la memoria, que en parte lo modulará - reconocer como recordar- y en parte se constituirá en condición de otros reconocimientos.

${ }^{3}$ Honneth, Reconocimiento y menosprecio. Sobre la fundamentación normativa de una teoría social, Katz, Madrid, 2010, 66-67.

${ }^{4}$ En torno a esta dinámica perversa y otras similares resulta provechoso consultar Alonso, M., Univer-
}

sales del odio. Creencias, emociones y violencia, Bakeaz, Bilbao, 2004.

5 Sobre el reconocimiento sacralizado del victimario como héroe-mártir puede consultarse: Casquete, J., En nombre de Euskal Herria. La religión política del nacionalismo vasco radical, Madrid, Tecnos, 2009

${ }^{6}$ No debe olvidarse que un sector mayoritario de la ciudadanía vasca ha expresado su mal reconocimiento a las víctimas de ETA en el no reconocimiento del desentendimiento, marginándolas de sus vidas, viviendo como si no existieran. Aurelio Arteta aborda esta cuestión en Mal consentido. La complicidad del espectador indiferente, Alianza, Madrid, 2010, desde la perspectiva de la complicidad con el mal ante el que se tiene una mirada indiferente.

7 Esto se nos muestra claramente cuando, para explicar la declaración de ETA del cese definitivo de su violencia se acude a argumentaciones estrictamente estratégicas, según las cuales, «en las condiciones actuales», la «lucha armada» «no es» positiva de cara a los fines perseguidos. Es decir, principalmente, se sigue sin renunciar a los supuestos inmorales del esquema anterior. 
${ }^{8}$ Cuando se contempla este panorama aparece la delicada cuestión de reconocer a víctimas que son o han sido también victimarios. Ante ella, hay que sostener que también al terrorista se le debe respetar en su dignidad, que también él, si acaba siendo víctima, en cuanto víctima es inocente, no ha «merecido» serlo, aunque «merezca» un trato punitivo acorde con los derechos humanos. Puede ser pertinente, ante esta problemática, hacerse cargo de la distinción entre reconocer a alguien como víctima y homenajearle por sus méritos en la contribución al bien público. Lo primero no implica lo segundo; incluso, cuando se trata de alguien que es a la vez víctima y victimario, recibirá un reconocimiento complejo en el que se incluye la contundente reprobación de su condición de perpetrador de violencia. Para abordar este tema, que aquí dejo solo apuntado, véase Bilbao, G., Jano en medio del terror. La inquietante figura del victimario-víctima, Bakeaz, Bilbao, 2009.

9 Sobre la participación de las víctimas del terrorismo, me remito a un estudio previo: Etxeberria, X., La participación social y politica de las víctimas del terrorismo, Bakeaz, Bilbao, 2007. Puede consultarse también: Margalit, A., Ética del recuerdo, Herder, Barcelona, 2002.

${ }^{10}$ Se la escuché en una mesa redonda que compartí con él, organizada por la Fundación Fernando Buesa.

${ }^{11}$ Por supuesto, seguirá habiendo grados diferentes de victimación entre las víctimas en función del sufrimiento injusto soportado - que también hay que tener presentes para el reconocimiento debido-, pero transversalmente a los tipos de violencia. Igualmente, hay grados diferentes de mal causado entre los perpetradores, respecto a los que debe asignárseles la correspondiente responsabilidad penal, también transversales a sus diversas modalidades de violencia (aquí, el impacto político de la violencia de los terroristas agranda el mal que causan).

${ }_{12}$ Ricoeur, P., Caminos de reconocimiento, FCE, México, 2006, 33; Honneth, A., «Reconocimiento y obligaciones morales», Revista Internacional de Filosofia Política, 8 (1996), 10.

13 Analiza esta cuestión hegeliana Jaeschke, W., «Il riconoscimento come principio dell'ordinamento statale e interstatale», Archivio di filosofía, 2-3 (2009), 189-198.

${ }^{14}$ En Fraser y Honneth, op. cit., 136. Se puede conexionar con esto el planteamiento hegeliano (Fenomenología del Espíritu, Valencia, Pre-textos, 2009) en el que se muestra cómo las autoconciencias del amo y el esclavo, con la correspondiente lucha asimétrica de dominio y sometimiento, no producen el reconocimiento buscado porque no hay reciprocidad. Esta relación preestatal, nos dirá el Hegel maduro, debe reconducirse hacia el reconocimiento simétrico entre personas iguales, lo constitutivo del Estado.

15 Esta categoría se enmarca muy adecuadamente en una concepción anamnética de la justicia, tal como nos la propone Mate, M. Reyes, «Por una justicia anamnética», Iglesia viva, 247 (2011).

16 «Riconoscimento, autenticità, autoriconoscimento», Archivio di Filosofia, 2-3 (2009), 209-217.

${ }_{17}$ Ricoeur, op. cit., 277.

18 Jelin, E., Los trabajos de la memoria, Siglo XXI, Buenos Aires, 2002, 69.

${ }^{19} \mathrm{He}$ abordado por mi parte estas cuestiones en Etxeberria, X., Dinámicas de la memoria y víctimas del terrorismo, Bakeaz, Bilbao, 2007.

${ }^{20} \mathrm{Mi}$ tendencia a sospechar de categorías únicas que quieren explicar lo que es una realidad compleja, me empuja a la empatía hacia la propuesta de Fraser con su «dualismo perspectivista» de distribución y reconocimiento, frente al «monismo del reconocimiento» de Honneth. Aunque luego me resulta reductor (¿monista en última instancia?) el que ella acabe queriendo sintetizarlo todo en la opción por la «paridad participativa» de los «sujetos autónomos» concebidos deontológico-formalmente. En cualquier caso, tengo la sensación de que ambos autores exageran retóricamente sus diferencias y no están suficientemente atentos a sacar provecho mutuo de sus afinidades.

${ }^{21}$ Honneth, Reconocimiento y menosprecio..., 10 y 12 .

${ }^{22}$ Honneth lo expresa más nítidamente en otro estudio ya citado, «Reconocimiento y obligaciones morales». Los humanos, señala: a) somos constitutivamente vulnerables en nuestras relaciones mutuas, lo que implica que precisamos la ayuda de reconocimientos adecuados de los otros para tener autorreferencias positivas; b) la experiencia de injusticia está siempre acompañada de una conmoción psíquica, en cuanto frustración de esa expectativa que tenemos respecto al otro en algo que afecta a nuestra propia identidad; es, por eso, a la vez daño personal y herida moral. Que esto se vivencia con toda su contundencia en la experiencia de las víctimas del terrorismo, es manifiesto.

${ }^{23}$ Ha elegido también otros tipos de víctimas, que no podemos olvidar: como, sistemáticamente, las ligadas al mundo empresarial, o, más ocasionalmente, las que han sido acusadas de corromper a la juventud vasca (por fomento de la drogadicción o conductas similares). Y están, además, por supuesto, las «víctimas colaterales», que se han asumido sin escrúpulos.

${ }^{24}$ Petrucciani, en op. cit., critica con razón la aparente linealidad causal que parece establecerse entre buen reconocimiento de los otros, identidad y autorrealización. Frente a esta direccionalidad funcional habría que plantearse más bien una circularidad de interacción mutua, que salva la autonomía de la víctima sin ignorar sus interdependencias.

${ }^{25}$ Otro pensador del reconocimiento, como es Taylor, también insiste en la conexión que tiene con la identidad, al concebir a esta modelada significativamente por el reconocimiento recibido. Lo hace, con todo, con un énfasis especial en las identidades culturales colectivas - que, matiza, deben ofrecer salvaguardas adecuadas para los derechos fundamentales de 
las personas-, que Honneth rechaza, y con una intensificación de la referencia a la vida buena, al conexionar a esta con la «negociación» que las personas hacemos con las propuestas de realización que nos ofrecen las culturas en las que somos socializados. Véanse sus trabajos: «Identidad y reconocimiento», Revista internacional de filosofia política, 7 (1996), 10-19; «La política del reconocimiento», en Taylor, C., Argumentos filosóficos, Paidós, Barcelona, 1997. 293-334.

${ }^{26}$ Ricoeur, op. cit., 36.

${ }^{27}$ Desarrollo este tema de la identidad, en conexión con las víctimas del terrorismo, en Etxeberria, $\mathrm{X}$., Identidad como memoria narrada y víctimas del terrorismo, Bakeaz, Bilbao, 2009.

${ }^{28}$ Reflexionan sobre esta vía: Todorov, T., Memoria del mal, tentación del bien, Península, Barcelona, 2002; y Ricoeur, P., La memoria, la historia, el olvido, Trotta, Madrid, 2003.

${ }^{29} \mathrm{He}$ abordado con amplitud esta cuestión en Etxeberria, X., «Historización de la memoria de las víctimas del terrorismo en el País Vasco», en Rivera, A. y Carnicero, C. (eds.), Violencia política: historia, memoria y víctimas, Maia, Madrid, 2010, 287-316.

30 Véase Todorov, T., Los abusos de la memoria, Paidós, Barcelona, 2008; así como la aplicación que hago de este tema a las víctimas del terrorismo en Etxeberria, X., Dinámicas de la memoria..

${ }^{31}$ Sobre las exigencias, en este terreno, de los colectivos organizados de víctimas, puede consultarse en internet el Comunicado Conjunto de Asociaciones y Fundaciones de Víctimas del Terrorismo: «Principios rectores para un modelo de fin de ETA sin impunidad», acordado en Madrid el 23-11-2010.

${ }^{32}$ Finelli, R., «Trame del riconoscimento in $\mathrm{He}-$ gel», Archivio di Filosofía, 2-3 (2009), 53.

${ }^{33}$ Sobre este tema considero muy pertinente el acercamiento de Galo Bilbao, al que me remito: Por una reconciliación asimétrica. De la "geometría» del terror a la de su superación, Bakeaz, Bilbao, 2008.

${ }^{34}$ En «Par-delà la reconnaissance. L'attention comme paradigme por une éthique asymetrique», $\mathrm{Al}$ ter. Revue de Phénoménologie, 18 (2010), 125-141. En este trabajo, Alloa hace una firme crítica al paradigma del reconocimiento, concretamente a lo que él entiende que son sus presupuestos epistemológico, simétrico y diádico. Y lo reconduce hacia el paradigma de la interatención, o atención conjunta. Personalmente, aparte de que el enfoque propuesto aquí para el reconocimiento no tiene exactamente esos presupuestos, considero que ambos paradigmas no se enfrentan, sino que se complementan. 